\title{
Growth of Large-Area Single- and Bi-Layer Graphene by Controlled Carbon Precipitation on Polycrystalline Ni Surfaces
}

\author{
Alfonso Reina ${ }^{1}$, Stefan Thiele ${ }^{2}$, Xiaoting Jia ${ }^{1}$, Sreekar Bhaviripudi ${ }^{3}$, Mildred S. Dresselhaus ${ }^{3,4}$, Juergen A. \\ Schaefer ${ }^{2}$, and Jing Kong ${ }^{3}(\bowtie)$ \\ ${ }^{1}$ Department of Materials Science and Engineering, Massachusetts Institute of Technology, Cambridge, Massachusetts 02139, USA \\ ${ }^{2}$ Institut für Physik and Institut für Mikro- und Nanotechnologien, Technische Universität Ilmenau, Ilmenau 98684, Germany \\ ${ }^{3}$ Department of Electrical Engineering and Computer Science, Massachusetts Institute of Technology, Cambridge, Massachusetts 02139, USA \\ ${ }^{4}$ Department of Physics, Massachusetts Institute of Technology, Cambridge, Massachusetts 02139, USA \\ Received: 27 April 2009/Revised: 16 May 2009/Accepted: 17 May 2009 \\ CTsinghua University Press and Springer-Verlag 2009. This article is published with open access at Springerlink.com
}

\begin{abstract}
We report graphene films composed mostly of one or two layers of graphene grown by controlled carbon precipitation on the surface of polycrystalline $\mathrm{Ni}$ thin films during atmospheric chemical vapor deposition (CVD). Controlling both the methane concentration during CVD and the substrate cooling rate during graphene growth can significantly improve the thickness uniformity. As a result, one- or two- layer graphene regions occupy up to $87 \%$ of the film area. Single layer coverage accounts for $5 \%-11 \%$ of the overall film. These regions expand across multiple grain boundaries of the underlying polycrystalline Ni film. The number density of sites with multilayer graphene/graphite ( $>2$ layers) is reduced as the cooling rate decreases. These films can also be transferred to other substrates and their sizes are only limited by the sizes of the Ni film and the CVD chamber. Here, we demonstrate the formation of films as large as $1 \mathrm{in}^{2}$. These findings represent an important step towards the fabrication of large-scale high-quality graphene samples.
\end{abstract}

\section{KEYWORDS}

Graphene, chemical vapor deposition, nickel catalyst, carbon nanomaterials

Exploring ways to synthesize graphene which allow scalability, have low fabrication cost and facilitate integration with other materials, could play an important role in both fundamental research and the realization of future graphene applications. Several graphene synthesis approaches have been developed, including: (1) exfoliation methods (both mechanical [1, 2] and chemical [3-8]); (2) graphitization of SiC surfaces $[9,10] ;$ (3) graphene precipitation/deposition on transition metal surfaces [11, 12]; (4) gas phase/ substrate-free formation of graphene sheets [13]. Procedures such as (1) and (4) produce free-standing graphene isolated from any substrate which enables the integration of graphene with other materials. Methods like (2) and (3) produce graphene bound to a specific substrate which limits the flexibility of these approaches. Recently, it has been shown that graphene films can be grown by ambient pressure chemical vapor deposition (CVD) on thin films of transition metals and isolated from their growth

Address correspondence to jingkong@mit.edu 
substrate [14-16]. This approach is promising for generating large scale graphene on a wide range of substrates. However, these films vary in thickness from 1 to $\sim 10$ layers across their area [14-16, 17]. Here, we present an important advance to further improve the thickness uniformity of these films. We show that the area of multilayer graphene regions on the film can be reduced and the regions with singleor bi-layer graphene (1-2 LG) can be increased to $87 \%$ of the overall film area.

The precipitation of monolayer and multilayer graphene from bulk transition metals is widely known $[18,19]$. It occurs due to the temperature-dependent solubility of carbon in transition metals. This concept has recently been used to produce 12 LG under either vacuum conditions $[11,19]$ or in an ambient pressure CVD process [14-17]. In our process, carbon is introduced into the bulk of thin ( $500 \mathrm{~nm}) \mathrm{Ni}$ films by decomposing a highly diluted hydrocarbon gas $\left(\mathrm{CH}_{4}\right)$. Graphene precipitation is promoted on the surface of the Ni films upon cooling of the $\mathrm{Ni}-\mathrm{C}$ solid solution. A summary of the three-stage process that is utilized is shown in Fig. 1. The samples are heated to $900{ }^{\circ} \mathrm{C}$ and annealed for $20 \mathrm{~min}$ at this temperature (stage 1) under $\mathrm{Ar}$ and $\mathrm{H}_{2}$ in order to smooth the Ni surface and to activate $\mathrm{Ni}$ grain growth. During stage 2, $\mathrm{CH}_{4}$ (typically around $0.5 \mathrm{vol} \%-1 \mathrm{vol} \%$ by controlling the flow rate) along with $\mathrm{H}_{2}$ is allowed to flow over the Ni surface at $1000{ }^{\circ} \mathrm{C} . \mathrm{CH}_{4}$ begins to decompose catalytically on the surface of $\mathrm{Ni}[21,22]$ and carbon diffuses into the $\mathrm{Ni}$ film. After $5 \mathrm{~min}$ of $\mathrm{CH}_{4}$ exposure, the $\mathrm{Ni}$ film is cooled down (stage 3) under $\mathrm{Ar}, \mathrm{H}_{2}$ and the same $\mathrm{CH}_{4}$ concentration (see Fig. 1 and Table 1 for exact flow rates). Based on previous models of non-equilibrium carbon segregation in $\mathrm{Ni}[19,23]$, when the $\mathrm{Ni}-\mathrm{C}$ solution is cooled down, graphene precipitates on the surface of the Ni film. We report that by controlling the amount of methane during our process and reducing the rate of substrate cooling in stage 3 , it is possible to obtain graphene films consisting of mostly 1-2 LG (see Fig. 2). The Ni films

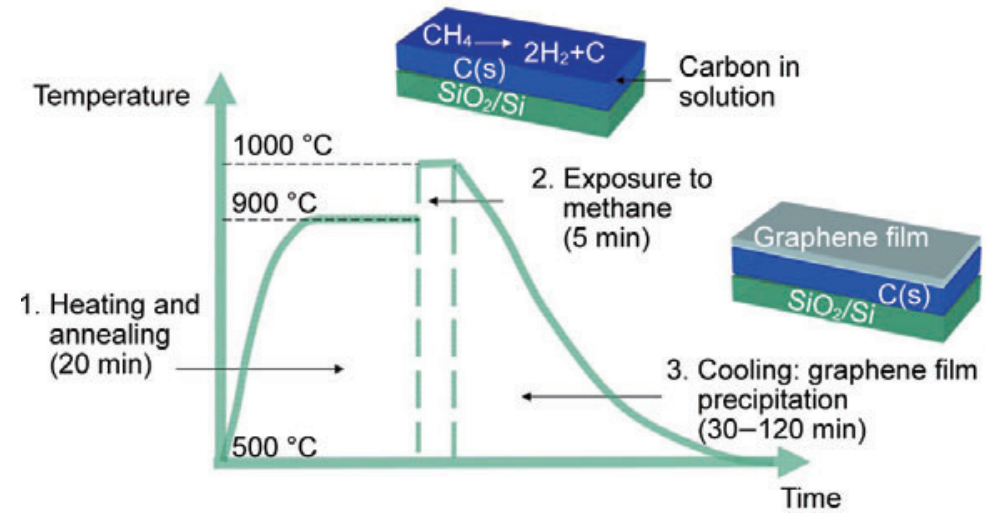

Figure 1 Illustration of the graphene growth process and its different stages (13). 1. The $\mathrm{Ni}$ film deposited on $\mathrm{SiO}_{2} / \mathrm{Si}$ is heated to $900{ }^{\circ} \mathrm{C}$ and annealed for $20 \mathrm{~min}$ under flowing $\mathrm{H}_{2}$ and $\mathrm{Ar}$ (400 and 600 standard cubic centimeter per minute (sccm), respectively). Here, Ni grain growth and surface smoothening occurs. 2. Exposure to $\mathrm{H}_{2}$ and $\mathrm{CH}_{4}$ for $5 \mathrm{~min}$. The flow rate of $\mathrm{H}_{2}$ is always $1400 \mathrm{sccm}$ in every run. The flow rates of $\mathrm{CH}_{4}$ used in the results presented in Table 1 are $6,7,8$, and $10 \mathrm{sccm}$ corresponding to concentrations of 0.4 vol\%, 0.5 vol\%, 0.6 vol\%, and 0.7 vol\%, respectively. $\mathrm{CH}_{4}$ is decomposed catalytically and the carbon produced is incorporated into the $\mathrm{Ni}$ film. 3. The substrate is cooled down from 1000 to $500{ }^{\circ} \mathrm{C}$ under $\mathrm{Ar}, \mathrm{H}_{2}(700 \mathrm{sccm}$ for both gases) and the same flow of $\mathrm{CH}_{4}$ is used as in stage 2. Times for this step are 15 to 120 min corresponding to cooling rates between 33.0 and $4.2{ }^{\circ} \mathrm{C} / \mathrm{min}$. At $500{ }^{\circ} \mathrm{C}$, the sample is taken out of the tube furnace and cooled rapidly to room temperature. For the case of a cooling rate of $100.0{ }^{\circ} \mathrm{C} / \mathrm{min}$, the sample is simply taken out of the furnace and cooled down to room temperature

Table 1 Types of graphene films obtained at different methane concentrations and cooling rates.

\begin{tabular}{|c|c|c|c|c|c|c|c|}
\hline \multirow{2}{*}{$X_{\text {methane }}(\mathrm{vol} \%)$} & \multicolumn{7}{|c|}{$\mathrm{d} T / \mathrm{d} t\left({ }^{\circ} \mathrm{C} / \mathrm{min}\right)$} \\
\hline & 100.0 & 33.0 & 25.0 & 16.6 & 8.3 & 5.5 & 4.2 \\
\hline 0.4 & \multicolumn{7}{|c|}{ No graphene film } \\
\hline 0.5 & \multicolumn{2}{|c|}{ No graphene film } & & \multicolumn{4}{|c|}{ B } \\
\hline 0.6 & \multicolumn{2}{|c|}{$A$} & & \multicolumn{4}{|c|}{ B } \\
\hline 0.7 & \multicolumn{7}{|c|}{ A } \\
\hline
\end{tabular}

A=films of type A (Figs. 2(a) and 2(b)). B=films of type B (Figs. 2(c) and 2(d)) 
utilized are polycrystalline due to their deposition method (E-beam evaporation or sputtering) with a thickness of $\sim 500 \mathrm{~nm}$. The role of the $\mathrm{Ni}$ grain size on the thickness variation of the graphene films has been discussed previously [24]. In this work, Ni films were deposited under conditions which give two different average Ni grain sizes of a few microns or a few tens of microns after annealing (i.e., after stage 1). Results are compared using Ni substrates with both grain sizes. The use of these types of $\mathrm{Ni}$ films is attractive due to their relatively simple fabrication and low cost compared to single crystalline $\mathrm{Ni}$. Transfer of the resulting graphene was done by wet-etching of the Ni film with a $3 \mathrm{wt} \%$ aqueous solution of hydrochloric acid. Before etching, a layer of poly(methyl methacrylate) (PMMA) was spincoated on the surface of the graphene film to serve as a support. The resulting PMMA/graphene layer was then manually laid on the target substrate $\left(\mathrm{SiO}_{2} / \mathrm{Si}\right.$ or TEM grids). The PMMA was finally removed by exposure to acetone in liquid or vapor form.

Two types of graphene films (A and B, shown in Fig. 2) with contrasting thickness variations can be obtained by controlling the methane concentration during CVD $\left(X_{\text {methane }}\right)$ and the rate of cooling $(\mathrm{d} T / \mathrm{d} t)$. Table 1 shows the conditions under which each type of film can be grown. Films of type A consist mostly of multilayer graphene and are grown with high $X_{\text {methane }}(0.7 \mathrm{vol} \%)$. It is observed that the $\mathrm{Ni}$ grain size plays a critical role in the thickness variation of the film, as also reported previously [24]. Multilayer graphene with more than two graphene layers (2+ $\mathrm{LG}$ ) tends to segregate around the grain boundaries of the polycrystalline Ni film (Figs. 2(a) and 2(b)). The thinnest regions that were identified (1-2 LG) grow at the center of the large $\mathrm{Ni}$ grains of the catalytic Ni film. These observations suggest that Ni grain boundaries act as preferential nucleation sites for multilayer
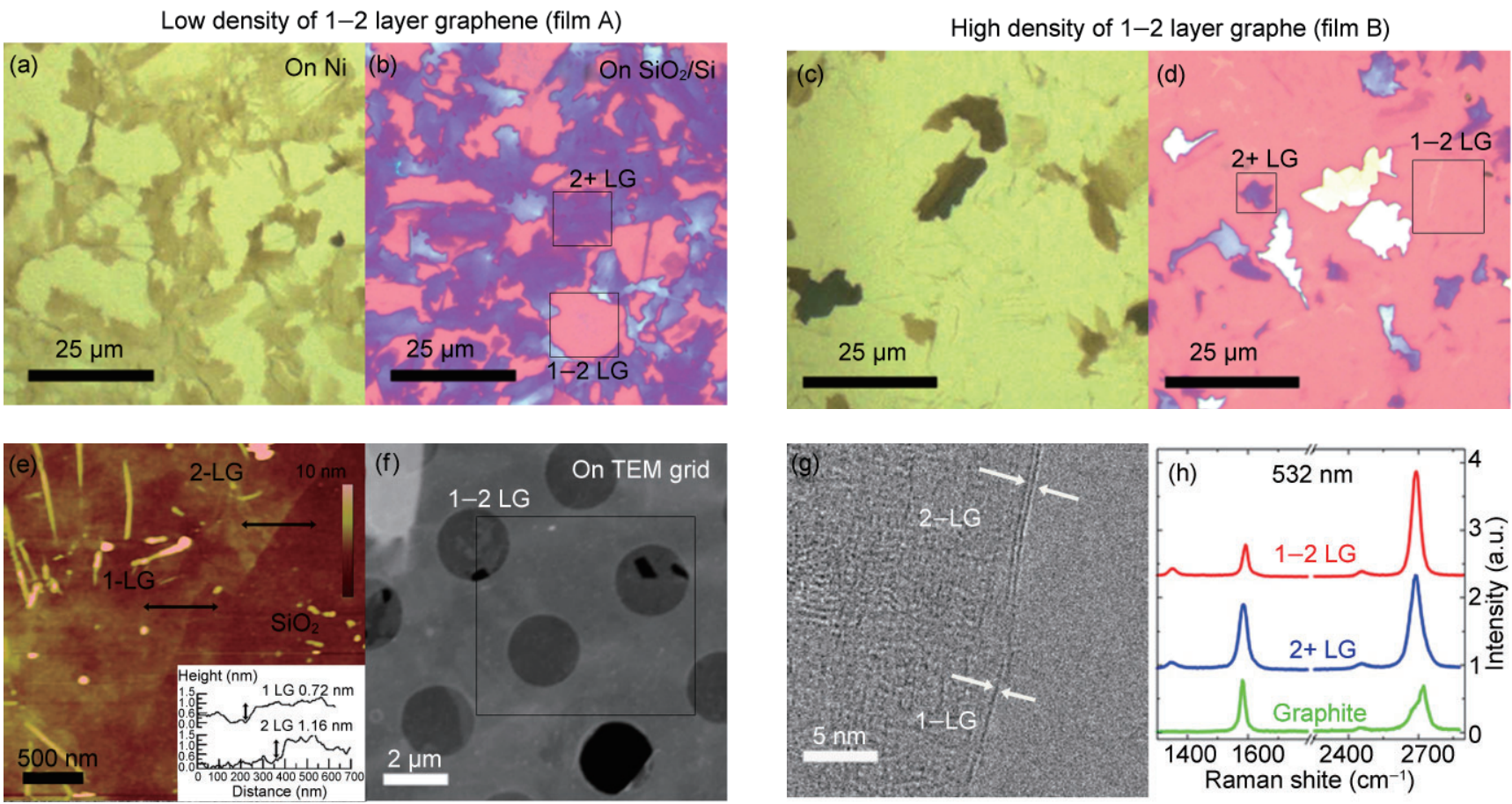

Figure 2 Two types of graphene films (types A and B) and their characterization. (a), (b) Type A film with low coverage of one- to two- layer regions (low $\left.\theta_{1-2 \mathrm{LG}}\right)$. (c), (d) Type B film with high coverage of one- to two- layer regions. (a) and (c) are optical images of the graphene films on $\mathrm{Ni},(b)$ and (d) are optical images of the graphene films transferred to $\mathrm{SiO}_{2} / \mathrm{Si}$. Transfer to $\mathrm{SiO}_{2} / \mathrm{Si}$ enables thickness analysis by optical contrast. (e) AFM image of a 1-2 layer region on $\mathrm{SiO}_{2} / \mathrm{Si}$ of a type $\mathrm{B}$ film. Inset shows the cross sectional height of 1 and 2 LG measured along the lines shown in the AFM tepographical image. ( $f$ ) SEM image of a 1-2 LG region of a type B film transferred to a TEM grid for thickness analysis. The regions remain freestanding across the circular openings of the grid. Dark areas suggest that the film broke at those sites. $(\mathrm{g}$ ) TEM image of a region consisting of 1-2 LG in a type B film (pink background in (d)). (h) Representative Raman spectra collected from a type $B$ film at regions consisting of 1-2 LG (shown in red) and 2+ LG ( 5 L, shown in blue). The $\mathrm{G}^{\prime}$ peak at $\sim 2700 \mathrm{~cm}^{-1}$ for $1-2 \mathrm{LG}$ is a single Lorentzian peak. The Raman spectra of graphite pieces found in the film (yellow clusters in optical image (d)) are shown in green. The laser wavelength used was 514 $\mathrm{nm}$ with a laser power of $1 \mathrm{~mW}$ and acquisition time of $5 \mathrm{~s}$ 
graphene or graphite. This can be explained by the fact that impurities in transition metals tend to segregate at grain boundaries [25, 26]. On closer scrutiny, comparison of Figs. 2(a) and 2(b) reveals that multilayer graphene was present at almost all the Ni grain boundaries, suggesting that the density of nucleation sites for graphene precipitation is high (as compared to graphene film type $\mathrm{B}$ which is discussed later). For a $\mathrm{CH}_{4}$ concentration of $0.7 \%-$ which always results in the growth of type A filmsthe sizes of 1-2 LG are independent of the cooling rate (see the summary in Table 2), but do depend strongly on the average grain size of the $\mathrm{Ni}$ film used for the synthesis. Therefore, Ni films with different average grain sizes produce 1-2 LG regions of different sizes [24].

Graphene films with their area consisting mostly of 1-2 LG (type B in Fig. 2) are grown by using intermediate $X_{\text {methane }}$ values $(0.5 \%-0.6 \%)$ and low cooling rates $\left(\mathrm{d} T / \mathrm{d} t<25{ }^{\circ} \mathrm{C} / \mathrm{min}\right)$. For this case, the film thickness variation obtained is significantly different from that obtained with higher $X_{\text {methane }}$ $(0.7 \%)$. It is observed that not all grain boundaries on the polycrystalline $\mathrm{Ni}$ show the nucleation of multilayers (Figs. 2(c) and 2(d)), resulting in an increase of the area fraction covered by 1-2 LG. AFM, TEM, Raman spectroscopy and optical microscopy were used to characterize these films (Figs. 2(e)-(h)). The heights of 1- and 2-LG on $\mathrm{SiO}_{2} / \mathrm{Si}$ as measured by AFM are 0.72 and $1.16 \mathrm{~nm}$, respectively (Fig. 2(e)). TEM confirmed that most of the film area consists of 1-2 LG (Figs. 2(f) and 2(g)). The Raman $G^{\prime}$ band $\left(\sim 2700 \mathrm{~cm}^{-1}\right)$ of 1- and 2-LG always has a single Lorentzian lineshape. For both cases, the linewidth usually lies in the range $30-40 \mathrm{~cm}^{-1}$, suggesting the absence of interlayer coupling. Furthermore, the relative intensity of the $G^{\prime}$ and $G$ bands varies randomly between 1- and 2-LG regions, possibly due to differences in doping levels [27]. Also, no difference in $\mathrm{G}^{\prime}$ frequency is observed between the 1- and 2-LG regions probed [28]. Therefore, it is not possible to distinguish between 1- and 2-LG using Raman spectroscopy alone. This is better done by optical microscopy (see discussion below and Electronic Supplementary Material (ESM)) or direct observation in a TEM. Four point probe measurements of the sheet resistance of the films yield values of $\sim 0.5$ $1 \mathrm{k} \Omega / \mathrm{sq}$ and 3-5 k $\Omega$ / sq for films of types $\mathrm{A}$ and $\mathrm{B}$, respectively. The difference in sheet resistance is attributed to the conduction through multilayer graphene which should have a larger contribution to the film conductivity in the case of films of type A.

The differences in the number of multilayer graphene sites between films of types A and B can be explained in terms of the differences in the methane concentrations and cooling rates used. Lower methane concentrations will result in relatively low carbon concentrations in the $\mathrm{Ni}$ film. Consequently,

Table 2 Description of films obtained with different $\mathrm{CH}_{4}$ concentrations and cooling rates

\begin{tabular}{|c|c|c|}
\hline \multirow{2}{*}{$X_{\text {methane }}(\mathrm{vol} \%)$} & \multicolumn{2}{|c|}{ Regime of $\mathrm{d} T / \mathrm{d} t\left({ }^{\circ} \mathrm{C} / \mathrm{min}\right)$} \\
\hline & $\operatorname{High}\left(100.0^{\circ} \mathrm{C} / \mathrm{min}\right)$ & $\operatorname{Low}\left(<25^{\circ} \mathrm{C} / \mathrm{min}\right)$ \\
\hline 0.5 & No graphene film & $\begin{array}{l}\text { B } \\
\theta_{1-2 L G} \text { depends on cooling rate; } \\
\rho_{2+L G} \text { is homogeneous across Ni surface; } \\
\text { full coverage of the graphene film on the Ni surface }\end{array}$ \\
\hline 0.6 & $\begin{array}{l}\text { A } \\
\theta_{1-2 L G} \text { similar to the size of Ni grains; } \\
\rho_{2+L G} \text { is homogeneous across the graphene film; } \\
\text { partial coverage of the graphene film on the Ni surface }\end{array}$ & $\begin{array}{l}\text { B } \\
\theta_{1-2 L G} \text { depends on cooling rate; } \\
\rho_{2+L G} \text { is inhomogeneous across the graphene film; } \\
\text { full coverage of the graphene film on the Ni surface }\end{array}$ \\
\hline 0.7 & $\begin{array}{l}\text { A } \\
\theta_{1-2 L G} \text { similar to the size of Ni grains; } \\
\rho_{2+L G} \text { is homogeneous across the graphene film; } \\
\text { full coverage of the graphene film on the Ni surface }\end{array}$ & $\begin{array}{l}\text { A } \\
\theta_{1-2 L G} \text { similar to the size of Ni grains; } \\
\rho_{2+L G} \text { is homogeneous across the graphene film; } \\
\text { full coverage of the graphene film on the Ni surface }\end{array}$ \\
\hline
\end{tabular}

A=films of type A (Figs. 2(a) and 2(b)). B=films of type B (Figs. 2(c) and 2(d)). $\theta_{1-2 L G}=$ area fraction occupied by one or two graphene layers. $\rho_{2+L G}=$ number density of multilayer sites with more than two graphene layers. 
this will promote a reduction of carbon segregation on the Ni surface during the cooling stage. The amount of segregation, for a given change in temperature $\mathrm{d} T / \mathrm{d} t$, depends on the magnitude of the solute oversaturation (which should be directly related to the methane flow rate) [29-31]. On the other hand, decreasing $\mathrm{d} T / \mathrm{d} t$ may promote segregation under conditions closer to equilibrium, therefore reducing the density of multilayer sites [32]. Note that with $0.5 \%$ methane concentration, only films of type B were obtained, whereas if the methane concentration was increased to $0.7 \%$, only films of type A were obtained. This is consistent with our ideas discussed above. Table 1 shows that at $0.6 \%$ methane, there was a transition from A to B type of film growth as the cooling rate was decreased. However, it was found that this methane concentration resulted in a partial graphene coverage of the Ni surface if high cooling rates $\left(33-100{ }^{\circ} \mathrm{C} / \mathrm{min}\right)$ were used (see Table 2). For the same methane concentration, using low cooling rates $\left(<25{ }^{\circ} \mathrm{C} / \mathrm{min}\right)$ resulted in full coverage but with an inhomogeneous density of multilayer sites. The best control over both graphene coverage and homogeneous density of multilayer sites was accomplished with methane concentrations of $0.5 \%$ and $0.7 \%$ for films of types A and B, respectively (see Table 2).

It was found that in type B films, grown with $X_{\text {methane }}=0.5 \%$, the area covered by 1-2 LG $\left(\theta_{1-2 \mathrm{LG}}\right)$ was dependent on the cooling rate (Table 2). Figure 3 shows that decreasing the cooling rate below $25{ }^{\circ} \mathrm{C} / \mathrm{min}$ during the segregation step further increased $\theta_{1-2 \mathrm{LG}}$ in type B films ( $X_{\text {methane }} \sim 0.5 \%$ ). In addition, the slower the cooling rate, the fewer the number of nucleation sites of multilayer graphene $\left(\rho_{2+\mathrm{LG}}\right)$. The decrease in the density of multilayer sites can be also attributed to a reduction of the segregation rate caused by the lowering of $\mathrm{d} T / \mathrm{d} t$. At low segregation rates, carbon atoms can diffuse for longer times before they coalesce to form graphene (diffusion limited nucleation) [30]. It can also be observed that as $\mathrm{d} T / \mathrm{d} t$ decreased, not only did $\rho_{2+\mathrm{LG}}$ decrease but the thickness of the multilayer pieces increased. This can be seen by the increase in the number of yellow or white regions (graphite) and the reduction in the number of purple or blue regions on the graphene film (Figs. 3(a)-(c)). This suggests that $\mathrm{dT} / \mathrm{d} t$ may only have an effect on the density of multilayer sites, and not on the amount of carbon segregating. Consequently, in the case of our slowest cooling rates, if fewer nucleation sites are available for the same amount of carbon segregating at the surface, an increase in the thickness of the multilayer graphene regions must be expected.

The cooling rate of the Ni film during graphene precipitation was used to obtain films with up to $87 \%$ of their area $\left(\theta_{1-2 \mathrm{LG}}=0.87\right)$ composed of no more than two layers of graphene (of which the single layer area made up 5\%-11\% of the total film area). The area fraction $\theta_{1-2 \mathrm{LG}}$ increased as the cooling rate was decreased and it can be tuned from $0.60-0.87$ for CVD processes using $X_{\text {methane }} \sim 0.5 \%$ (Fig. 4). The
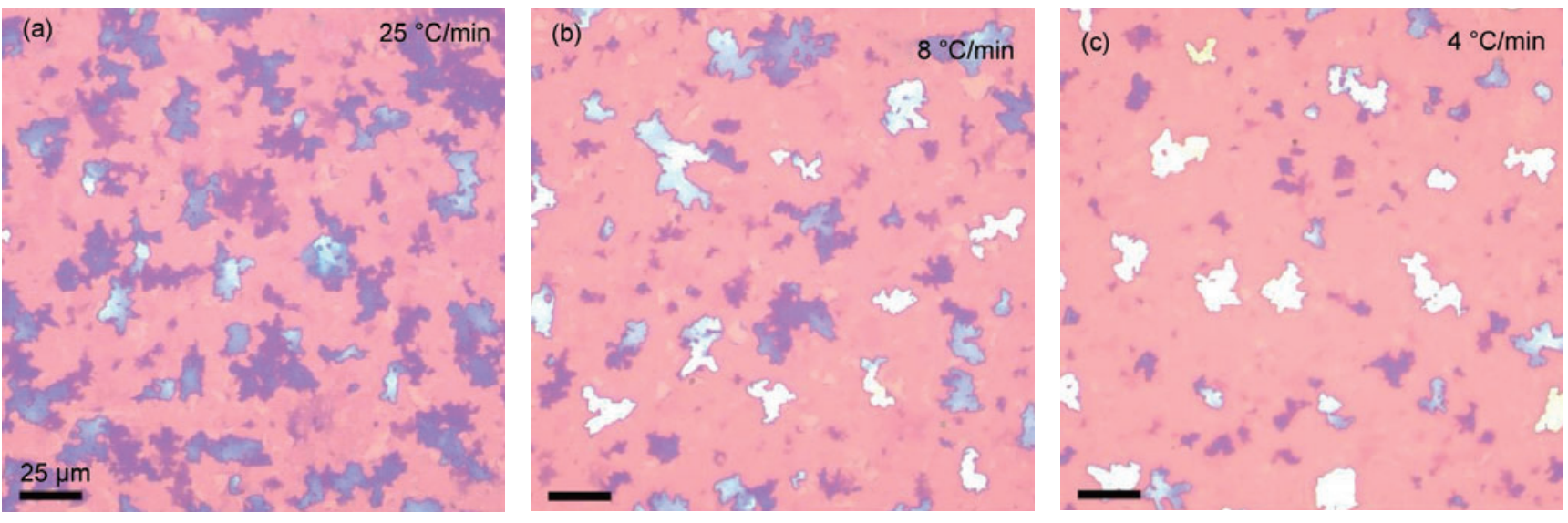

Figure 3 Effect of the cooling rate on type B films which were grown with a $\mathrm{CH}_{4}$ concentration of $0.5 \%$. (a)-(c) Optical images of graphene films transferred to $\mathrm{SiO}_{2} / \mathrm{Si}$ grown with decreasing cooling rate as indicated. The number of nucleation sites with multilayer graphene decreases as the cooling rate decreases, leading to an increase of the 1-2 LG region (pink background). Scale bars are all $25 \mu \mathrm{m}$ 

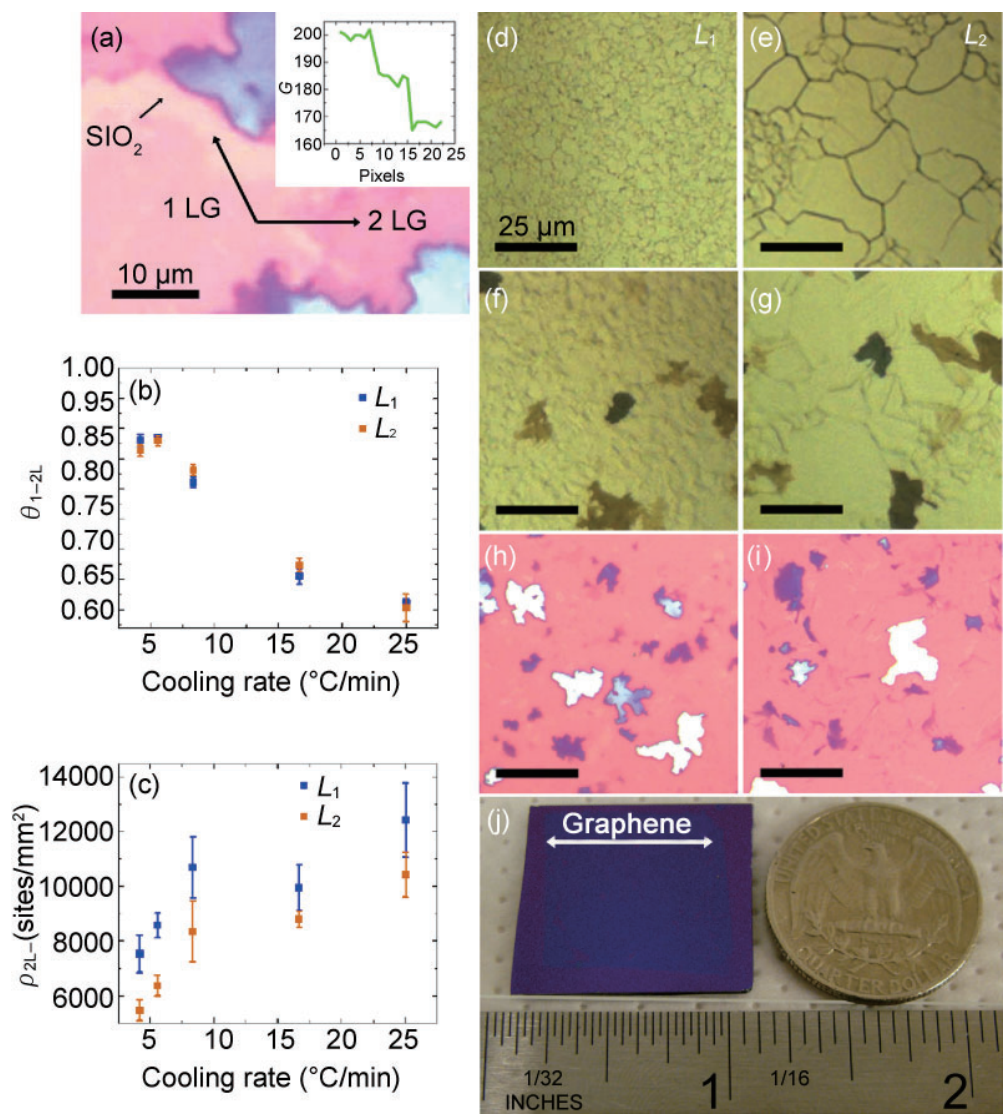

Figure 4 Quantification of single and bilayer graphene coverage of graphene films grown on Ni with different grain sizes $\left(L_{1}\right.$ and $\left.L_{2}\right)$. (a) Optical recognition of 1 - and 2-LG with the $\{G\}$ values extracted from the RGB image of graphene films on $\mathrm{SiO}_{2} / \mathrm{Si}$. $\{G\}$ decreases in a stepwise manner from bare $\mathrm{SiO}_{2}$ to one and to two graphene layers (inset in (a)): $\{G\}_{\text {bare } \mathrm{SiO}_{2}}=200$ and the measured $\Delta\{G\}$ values for the $1-\mathrm{L}$ and $2-\mathrm{L}$ regions shown are 15 and 33 , respectively (see inset). The expected $\Delta\{G\}$ for $1-L$ and 2-L HOPG are 16 and 30, respectively (see ESM). (b) Area fraction ( $\left.\theta_{1-2 L G}\right)$ covered by no more than two graphene layers as a function of cooling rate for graphene films synthesized with Ni grain sizes $L_{1}$ and $L_{2}$. (c) Number of sites per $\mathrm{mm}^{2}$ with more than two graphene layers $\left(\rho_{2+L G}\right)$ vs $d T / d t$. The two different Ni films with grain sizes $L_{1}$ and $L_{2}$ show a similar dependence on cooling rate. Optical images of the two grain sizes are shown in (d) and (e). Graphene films grown on the two types of Ni films before ((f) and (g)) and after transferring to $\mathrm{SiO}_{2} / \mathrm{Si}((\mathrm{h})$ and $(\mathrm{i}))$. The area covered by 1 -2 LG is independent of the Ni grain size. Scale bars in (d)-(i): $25 \mu \mathrm{m}$. (j) Photograph of a large graphene film with $\sim 87 \%$ of its area covered by $1-2 \mathrm{LG}$. The size of the films fabricated is only limited by the sizes of the Ni film and the CVD chamber employed

model, the color of each pixel in an image is represented by the intensities of the three primary colors-red, green, and blue, hence used as its name. When graphene is present on $300 \mathrm{~nm} \mathrm{SiO}{ }_{2} / \mathrm{Si}$, it creates an enhanced absorption at wavelengths around $500 \mathrm{~nm}$ $[34,35]$ corresponding to the color green. Therefore, the green component, $\{G\}$ of our optical images can be used to identify the contrast created by the CVD graphene film with respect to the underlying $\mathrm{SiO}_{2}$ (Fig. $4(\mathrm{a})$ ). This enables us to identify regions with down to 1- and 2-LG in an automated way (see ESM). Such a contrast in $\{G\}$ was also measured for pieces of exfoliated graphene (from highly oriented pyrolytic graphite (HOPG)) on $\mathrm{SiO}_{2} / \mathrm{Si}$ and was used as a calibration for the identification of 1or 2- LG derived from our CVD process (see ESM). The coverage, $\theta_{1-2 \mathrm{LG}}$ plotted in Fig. 4(b) represents the fraction of pixels identified as containing no more than two graphene layers (pink background in images of Fig. 3). Optical images at 50x magnification, with 3900 by 3090 pixels $(289 \mu \mathrm{m} \times 229 \mu \mathrm{m})$, were used for this analysis. It was also observed that $\theta_{1-2 \mathrm{LG}}$ is independent of the grain size of the Ni film used to synthesize graphene (Figs. 4(b) and $4(\mathrm{c})$ ). Two Ni grain sizes $\left(L_{1}\right.$ and $\left.L_{2}\right)$ were used in our experiments and their images are shown in Figs. 4(d) and 4(e). Optical images of graphene grown on both $\mathrm{Ni}$ grain structures and transferred to $\mathrm{SiO}_{2} / \mathrm{Si}$ are shown in Figs. 4(f)-(i). This comparison is important since the grain sizes of transition

density of sites consisting of multilayer graphene with more than two layers, $\rho_{2+\mathrm{LG}}$ can be decreased by $50 \%$ on going from the highest to the lowest cooling rate tested (Fig. 4). The quantification of the area percentage plotted in Fig. 4 was done by comparing optical images of the graphene films on $\mathrm{SiO}_{2} / \mathrm{Si}$ with bare $\mathrm{SiO}_{2} / \mathrm{Si}$ substrates. Each pixel of the optical images can be expressed in the RGB (red green blue) color model [33] which is used for image display and representation in electronic systems. In this metal thin films vary depending on film thickness, residual stress and deposition conditions [36, 37]. Lastly, these films are also transferable to other substrate materials, similar to the way such transfers have been reported previously [15]. Graphene films of up to $1 \mathrm{in}^{2}$ in size and with high area fractions of 1 -2 LG have been fabricated (Fig. 4(j)). Their sizes are limited only by the size of the Ni film used and the CVD chamber size.

In conclusion, we have demonstrated the 
possibility of growing graphene films with up to $87 \%$ of their area composed of no more than two graphene layers and which can also be transferred to insulating substrates. This was accomplished by controlling both the carbon concentration and the substrate cooling rate during the CVD process. Under a suitable carbon concentration $\left(0.5 \% \mathrm{CH}_{4}\right.$ in our case), the cooling rate can be utilized to decrease the number of nucleation sites of multilayer graphene on the film (by a factor of two) and to increase significantly the area covered by sections with 1-2 LG. Further quantitative analysis (for example, the carbon concentration inside the $\mathrm{Ni}$ film for substrates treated with different $\mathrm{CH}_{4}$ exposures and cooling rates) is currently being undertaken in order to gain a deeper understanding of this process. Nevertheless, our results suggest the possibility of dramatically improving the thickness uniformity of graphene films by controlling the process parameters in our method. Therefore, ambient pressure CVD may be a viable route to control the growth of single graphene layers over large scales.

\section{Acknowledgements}

This work was partly supported by the Materials, Structures and Devices (MSD) Focus Center, one of the five centers of the Focus Center Research Program, a Semiconductor Research Corporation program. Support from NSF/CTS 05-06830 (X. J. and M. S. D) and NSF / DMR07-04197 (A. R. and M. S. D.) is also acknowledged. Raman measurements were carried out in the George R. Harrison Spectroscopy Laboratory supported by NSF-CHE 0111370 and NIH-RR02594 grants. The authors acknowledge Mario Hofmann for help in preparation of graphic illustrations for potential cover art and Gerardo Martinez and Arturo Ponce Pedraza for providing images for the potential cover art.

Electronic Supplementary Material: Details of the automated recognition of regions of one- and twolayer graphene by computer programs using optical images are available in the online version of this article at http://dx.doi.org/10.1007/s12274-009-9059-y and are accessible free of charge.

\section{References}

[1] Novoselov, K. S.; Jiang, D.; Schedin, F.; Booth, T. J.; Khotkevich, V. V.; Morozov, S. V.; Geim, A. K. Twodimensional atomic crystals. Proc. Natl. Acad. Sci. USA 2005, 102, 10451-10453.

[2] Blake, P.; Brimicombe, P. D.; Nair, R. R.; Booth, T. J.; Jiang, D.; Schedin, F.; Ponomarenko, L. A.; Morozov, S. V.; Gleeson, H. F.; Hill, E. W.; Geim, A. K.; Novoselov, K. S. Graphene-based liquid crystal device. Nano Lett. 2008, 8, 1704-1708.

[3] Stankovich, S.; Dikin, D. A.; Piner, R. D.; Kohlhaas, K. A.; Kleinhammes, A.; Jia, Y.; Wu, Y.; Nguyen, S. T.; Ruoff, R. $\mathrm{S}$. Synthesis of graphene-based nanosheets via chemical reduction of exfoliated graphite oxide. Carbon 2007, 45, 1558-1565.

[4] Eda, G.; Fanchini, G.; Chhowalla, M. Large-area ultrathin films of reduced graphene oxide as a transparent and flexible electronic material. Nat. Nanotechnol. 2008, 3, 270-274.

[5] Hernandez, Y.; Nicolosi, V.; Lotya, M.; Blighe, M.; Sun, Z.; De, S.; McGovern, I. T.; Holland, B.; Byrne, M.; Gun'ko, Y. K.; Boland, John J.; Niraj, P.; Duesberg, G.; Krishnamurthy, S.; Goodhue, R.; Hutchison, J.; Scardaci, V.; Ferrari, Andrea C.; Coleman, Jonathan N. High-yield production of graphene by liquid-phase exfoliation of graphite. Nat. Nanotechnol. 2008, 3, 563-568.

[6] Li, D.; Mueller, Marc B; Gilje, S.; Kaner, Richard B.; Wallace, Gordon $\mathrm{G}$. Processable aqueous dispersions of graphene nanosheets. Nat. Nanotechnol. 2008, 3, 101-105.

[7] Li, X.; Zhang, G.; Bai, X.; Sun, X.; Wang, X.; Wang, E.; Dai, H. Highly conducting graphene sheets and LangmuirBlodgett films. Nat. Nanotechnol. 2008, 3, 538-542.

[8] Worsley, K. A.; Ramesh, P.; Mandal, S. K.; Niyogi, S.; Itkis, M. E.; Haddon, R. C. Soluble graphene derived from graphite fluoride. Chem. Phys. Lett. 2007, 445, 51-56.

[9] Berger, C.; Song, Z. M.; Li, T. B.; Li, X. B.; Ogbazghi, A. Y.; Feng, R.; Dai, Z. T.; Marchenkov, A. N.; Conrad, E. H.; First, P. N.; de Heer, W. A. Ultrathin epitaxial graphite: 2-D electron gas properties and a route toward graphenebased nanoelectronics. J. Phys. Chem. B 2004, 108, 19912-19916.

[10] Berger, C.; Song, Z. M.; Li, X. B.; Wu, X. S.; Brown, N.; Naud, C. Mayou, D.; Li, T. B.; Hass, J.; Marchenkov, A. N.; Conrad, E. H.; First, P. N.; de Heer, W. A. Electronic confinement and coherence in patterned epitaxial 
graphene. Science, 2006, 312, 1191-1196.

[11] Sutter, P. W.; Flege, J. -I.; Sutter, E. A. Epitaxial graphene on ruthenium. Nat. Mater. 2008, 7, 406-411.

[12] Pan, Y.; Shi, D. X.; Gao, H. J. Formation of graphene on Ru(0001) surface. Chin. Phys. 2007, 16, 3151-3153.

[13] Dato, A.; Radmilovic, V.; Lee, Z. H.; Phillips, J.; Frenklach, M. Substrate-free gas-phase synthesis of graphene sheets. Nano Lett. 2008, 8, 2012-2016.

[14] Yu, Q. K.; Lian, J.; Siriponglert, S.; Li, H.; Chen, Y. P.; Pei, S. -S. Graphene segregated on Ni surfaces and transferred to insulators. Appl. Phys. Lett. 2008, 93, 113103.

[15] Reina, A.; Jia, X. T.; Ho, J.; Nezich, D.; Son, H. B.; Bulovic, V.; Dresselhaus, M. S.; Kong, J. Large area, fewlayer graphene films on arbitrary substrates by chemical vapor deposition. Nano Lett. 2009, 9, 30-35.

[16] Kim, K. S.; Zhao, Y.; Jang, H.; Lee, S. Y.; Kim, J. M.; Kim, K. S.; Ahn, J. -H.; Kim, P.; Choi, J. -Y.; Hong, B. H. Largescale pattern growth of graphene films for stretchable transparent electrodes. Nature 2009, 457, 706-710.

[17] De Arco, L. G.; Yi, Z.; Kumar, A.; Chongwu, Z., Synthesis, transfer, and devices of single- and few-layer graphene by chemical vapor deposition. IEEE Trans. Nanotechnol. 2009, 8, 135-138.

[18] Fujita, D.;Yoshihara, K. Surface precipitation process of epitaxially grown graphite (0001) layers on carbondoped nickel(111) surface. J. Vac. Sci. Technol. A 1994, 12, 2134-2139.

[19] Shelton, J. C.; Patil, H. R.; Blakely, J. M. Equilibrium segregation of carbon to a nickel (111) surface: A surface phase transition. Surf. Sci. 1974, 43, 493-520.

[20] Loginova, E.; Bartelt, N. C.; Feibelman, P. J.; McCarty, K. F. Evidence for graphene growth by $\mathrm{C}$ cluster attachment. New J. Phys. 2008, 10, 093026.

[21] Muradov, N. Z. How to produce hydrogen from fossil fuels without $\mathrm{CO}_{2}$ emission. Int. J. Hydrogen Energ. 1993, 18, 211-215.

[22] Takenaka, S.; Shigeta, Y.; Tanabe, E.; Otsuka, K. Methane decomposition into hydrogen and carbon nanofibers over supported $\mathrm{Pd}-\mathrm{Ni}$ catalysts: Characterization of the catalysts during the reaction. J. Phys. Chem. B 2004, 108, 7656-7664.

[23] Fujita, D.; Homma, T. Surface precipitation of graphite layers on carbon-doped nickel and their stabilization effect against chemisorption and initial oxidation. Surf. Interface Anal. 1992, 19, 430-434.

[24] Thiele, S.; Reina, A.; Healey, P.; Kedzierski, J.; Wyatt, P.;
Hsu, P. L.; Keast, C.; Schaefer, J.; Kong, J. Engineering polycrystalline Ni films to improve thickness uniformity of the chemical vapor deposition grown graphene films. Submitted to Nanotechnology.

[25] Wang, Y. M.; Cheng, S.; Wei, Q. M.; Ma, E.; Nieh, T. G.; Hamza, A. Effects of annealing and impurities on tensile properties of electrodeposited nanocrystalline Ni. Scripta Mater. 2004, 51, 1023-1028.

[26] Shen, T. D.; Schwarz, R. B.; Feng, S.; Swadener, J. G.; Huang, J. Y.; Tang, M.; Zhang, H. Z.; Vogel, S. C.; Zhao, Y. S. Effect of solute segregation on the strength of nanocrystalline alloys: Inverse Hall-Petch relation. Acta Mater. 2007, 55, 5007-5013.

[27] Das, A.; Pisana, S.; Chakraborty, B.; Piscanec, S.; Saha, S. K.; Waghmare, U. V.; Novoselov, K. S.; Krishnamurthy, H. R.; Geim, A. K.; Ferrari, A. C.; Sood, A. K. Monitoring dopants by Raman scattering in an electrochemically top-gated graphene transistor. Nat. Nanotechnol. 2008, 3, 210-215.

[28] Lee, D. S.; Riedl, C.; Krauss, B.; von Klitzing, K.; Starke, U.; Smet, J. H. Raman spectra of epitaxial fraphene on $\mathrm{SiC}$ and of epitaxial graphene transferred to $\mathrm{SiO}_{2}$. Nano Lett. 2008, 8, 4320-4325.

[29] Frade, J. R. Kinetics of nucleation and growth. 1. Reation controlled growth. J. Mater. Sci. 1993, 28, 6715-6718.

[30] Frade, J. R. Kinetics of nucleation and growth. 2. Diffusioncontrolled growth. J. Mater. Sci. 1994, 29, 169-174.

[31] Gambaryan-Roisman, T.; Litovsky, E.; Shapiro, M.; Shavit, A. Reaction-diffusion model of surface and grain boundary segregation kinetics. Int. J. Heat Mass Tran. 2000, 43, 4135-4151.

[32] Song, S.; Yuan, Z.; Xu, T. Non-equilibrium segregation of boron at austenite grain boundaries. J. Mater. Sci. Lett. 1991, 10, 1232-1234.

[33] Foley, J. D.; van Dan, A.; Feiner, S, K.; Hughes, J. F. Computer Graphics: Principles and Practice; AddisonWesley systems programming series: New Jersey, 1995.

[34] Blake, P.; Hill, E. W.; Neto, A. H. C.; Novoselov, K. S.; Jiang, D.; Yang, R. ; Booth, T. J. ; Geim, A. K. Making graphene visible. Appl. Phys. Lett. 2007, 91, 063124.

[35] Roddaro, S.; Pingue, P.; Piazza, V.; Pellegrini, V.; Beltram, F. The optical visibility of graphene: Interference colors of ultrathin graphite on $\mathrm{SiO}_{2}$. Nano Lett. 2007, 7, 2707-2710.

[36] Thompson, C. V. Grain growth in thin films. Annu. Rev. Mater. Sci. 1990. 20, 245-268.

[37] Thompson, C. V.; Carel, R. Stress and grain growth in thin films. J. Mech. Phys. Solids 1996, 44, 657-673. 